\title{
Effect of lipoic acid combined with paclitaxel on breast cancer cells
}

\author{
B.J. $\mathrm{Li}^{1 *}$, X.Y. Hao ${ }^{1 *}$, G.H. Ren ${ }^{2}$ and Y. Gong ${ }^{1}$ \\ 'Department of the Galactophore \& Thyroid, \\ People's Hospital of XinJiang Uygur Autonomous Region, Urumqi, China \\ ${ }^{2}$ Mammary Gland Thyroid Surgery, \\ The Third Affiliated Hospital to XinJiang Medical University, Urumqi, Xinjiang, China \\ *These authors contributed equally to this study. \\ Corresponding author: G.H. Ren \\ E-mail: zhizihuakaioo@163.com \\ Genet. Mol. Res. 14 (4): 17934-17940 (2015) \\ Received August 17, 2015 \\ Accepted October 11, 2015 \\ Published December 22, 2015 \\ DOI http://dx.doi.org/10.4238/2015.December.22.18
}

ABSTRACT. Breast cancer is the most common gynecologic tumor globally that threatens women's health. Lipoic acid is a type of antioxidant that can alleviate oxidative stress damage. Studies showed that lipoic acid could inhibit the proliferation of tumor cells in cervical cancer and colon cancer. This paper intends to explore the combined effect of lipoic acid and paclitaxel on breast cancer cells. Breast cancer MCF-7 cells were divided into four groups: control group, lipoic acid group, paclitaxel group, and a combination group. MTT was applied to detect the drugs' influence on breast cancer cell proliferation. A colony formation test was used to determine the effects on breast cancer cell clone formation rate. Western blot was performed to detect the effects on nuclear factor (NF)-кB. Lipoic acid alone can inhibit tumor cell proliferation and clone formation with time dependence. Compared with the control, paclitaxel alone can significantly suppress tumor cell proliferation and clone formation $(P<0.05)$. Lipoic acid and paclitaxel in combination obviously strengthened their individual inhibitory effects on tumor cells $(P<0.05)$. Compared with 
the paclitaxel alone group, the combination group exhibited more remarkable inhibitory effect $(P<0.05)$. Lipoic acid alone or combined with paclitaxel can inhibit NF-kB expression and inhibit breast cancer cell proliferation.

Key words: Lipoic acid; Paclitaxel; Breast cancer; NF-кB

\section{INTRODUCTION}

Breast cancer is one of the most common tumors in women worldwide. Due to genetic factors, lifestyle, and environmental factors, the incidence of breast cancer increases yearly and is trending toward younger women. It usually has complicated etiology and multiple-organ metastasis (Li et al., 2011; Wei et al., 2013). Its incidence in China has already exceeded that of cervical cancer. Thus, clinical doctors urgently need to find a reasonable treatment to reduce its incidence. Although breast cancer patients' quality of life and survival time have greatly increased, their mortality has not been reduced significantly (Golubnitschaja et al., 2013; Khurshid et al., 2013) (Golubnitschaja et al., 2013; Khurshid et al., 2013). At present, breast cancer treatments are mainly comprehensive, including surgery, adjuvant chemotherapy, radiotherapy, and immunotherapy, etc. Among them, chemotherapy is an important way to alleviate advanced breast cancer pain and prolong the survival period (Park et al., 2015; Wardhe et al., 2015) (Park et al., 2015; Wardle et al., 2015). Therefore, selection of a reasonable chemotherapy drug could be helpful for improving the quality of life and reducing the economic burden experienced by breast cancer patients (Abouharb and Moulder, 2015) (Abouharb \& Moulder, 2015).

Paclitaxel is derived from Taxus chinensis and indicated for use in a variety of tumors, including breast cancer, ovarian cancer, and non-small cell lung cancer. As a first line drug for breast cancer, paclitaxel presents a good effect (Carbognin et al., 2015; Tang et al., 2015)(Carbognin et al., 2015; Tang et al., 2015). However, in clinical use, a single paclitaxel treatment often cannot restrain the breast cancer progress. It should be used in combination with other drugs (Riccardi et al., 2015) (Ricciardi et al., 2015). Lipoic acid (LA) is a strong antioxidant, known as a "natural antioxidant" because it exhibits both water-soluble and fat-soluble properties. LA belongs to the family of vitamin B compounds and is a coenzyme in a variety of enzyme complexes (Asci et al., 2015) (Asci et al., 2015). LA can play a protective role in diabetes and diabetic complications, as well as being used following ischemia-reperfusion injury in critical organs such as heart, brain, and kidney (Bingham et al., 2014) (Bingham et al., 2014). Recent research confirmed that LA can inhibit cancer cell proliferation in cervical cancer and colon cancer (Damnjanovic et al., 2014) (Damnjanovic et al., 2014). This study intends to explore the possible mechanisms of LA alone and with paclitaxel application in breast cancer cells.

\section{MATERIAL AND METHODS}

\section{Main reagents and instruments}

MCF-7 cell line was bought from the cell bank of Chinese academy of sciences. LA, paclitaxel, and enzyme-EDTA were obtained from Sigma Aldrich (St. Louis, MO, USA). DMEM medium was purchased from Gibco (Carlsbad, CA, USA). Fetal bovine serum (FBS) and penicillinstreptomycin were from Hyclone (Logan, Utah, USA). PVDF membrane was bought from Pall Life Sciences (Port Washington, NY, USA). MTT reagents, dimethyl sulfoxide, and western blot-related 
chemical reagents were from Shanghai Beyotime Biotechnology Co., Ltd. (Shanghai, China). ECL reagent was obtained from Amersham Biosciences (Piscataway, NJ, USA). NF-kB primary antibody and HRP tag IgG second antibody were bought from Cell Signaling (Danvers, Massachusetts, USA). Other reagents were purchased from Shanghai Sangon Biotechnology Co., Ltd. (Shanghai, China). Labsystem Version 1.3.1 microplate reader was bought from Bio-rad (Hercules, CA, USA).

\section{Cell culture and grouping}

MCF-7 breast cancer cells were seeded in cell cultivation bottles at $1 \times 10^{6} / \mathrm{cm}^{2}$ maintained in DMEM medium (containing 10\% FBS, $100 \mathrm{U} / \mathrm{mL}$ penicillin, and $100 \mu \mathrm{g} / \mathrm{mL}$ streptomycin) at $37^{\circ} \mathrm{C}$ and $5 \% \mathrm{CO}_{2}$. Based on previous studies (Damnjanovic et al., 2014; Lim et al., 2015) (Damnjanovic et al., 2014; Lim et al., 2015), MCF-7 cells were randomly divided into four groups, the control group; LA-alone group, treated with $50 \mu \mathrm{M} \mathrm{LA}$; paclitaxel-alone group, treated with $20 \mu \mathrm{g} / \mathrm{mL}$ paclitaxel; and combined group, which received $50 \mu \mathrm{M} \mathrm{LA}$ and $20 \mu \mathrm{g} / \mathrm{mL}$ paclitaxel.

\section{MTT assay}

After being cultured for 24, 48, and $72 \mathrm{~h}$, the cells in each group were digested and counted. Then the cells were seeded to the 96 -well plate at 3000 cells/well with five replicates. MTT solution $(20 \mu \mathrm{L}, 5 \mathrm{~g} / \mathrm{L})$ was added to each well and wells were cultured at $37^{\circ} \mathrm{C}$ and $5 \% \mathrm{CO}_{2}$ for 4 h. After adding $150 \mu \mathrm{L}$ DMSO for $10 \mathrm{~min}$, the absorbance (OD) value of each well was detected by microplate reader at a wavelength of $570 \mathrm{~nm}$ to calculate the cell proliferation rate.

\section{Colony formation assay}

Cells in the logarithmic phase were collected and seeded in a 60-mm dish at 50, 100, and 200 cells/dish. After being cultured for two to three weeks, cell growth was stopped when a visible clone appeared. The cells were fixed with methanol for $15 \mathrm{~min}$ and dyed by Giemsa solution. Colony formation rate $(\%)=($ colony number/seeded cells) $100 \mathrm{X}$. The experiment was repeated three times.

\section{Western blot}

The cells were digested with lysis buffer. Total protein was separated by denaturing with $10 \%$ SDS-polyacrylamide gel electrophoresis. Detection was performed with chemiluminescence and calculated with Quantity One. Protein level changes were determined by four replications.

\section{Statistical analysis}

All statistical analyses were performed using the SPSS13.0 software (Chicago, IL, USA). Numerical data are reported as means and standard deviation ( \pm SD). Differences between multiple groups were analyzed using one-way ANOVA or the LSD test. $P<0.05$ was considered to be significant.

\section{RESULTS}

\section{LA and paclitaxel effect on breast cancer cell proliferation}

MTT assay was applied to detect LA alone or combined with paclitaxel effect on MCF7 cell proliferation. Examination showed that LA alone could inhibit tumor cell proliferation after 
$24 \mathrm{~h}$ but without statistical difference $(P>0.05)$. LA alone could obviously suppress tumor cell proliferation after $48 \mathrm{~h}$ or $72 \mathrm{~h}(\mathrm{P}<0.05)$, suggesting that LA has inhibitory effects on breast cancer cell proliferation and this effect was time-dependent. Paclitaxel alone can significantly inhibit tumor cell proliferation $(P<0.05)$, also with time dependence. Combined LA and paclitaxel for $24 \mathrm{~h}$ could inhibit breast cancer cell proliferation more significantly than paclitaxel alone $(P<0.05$, Figure 1$)$.

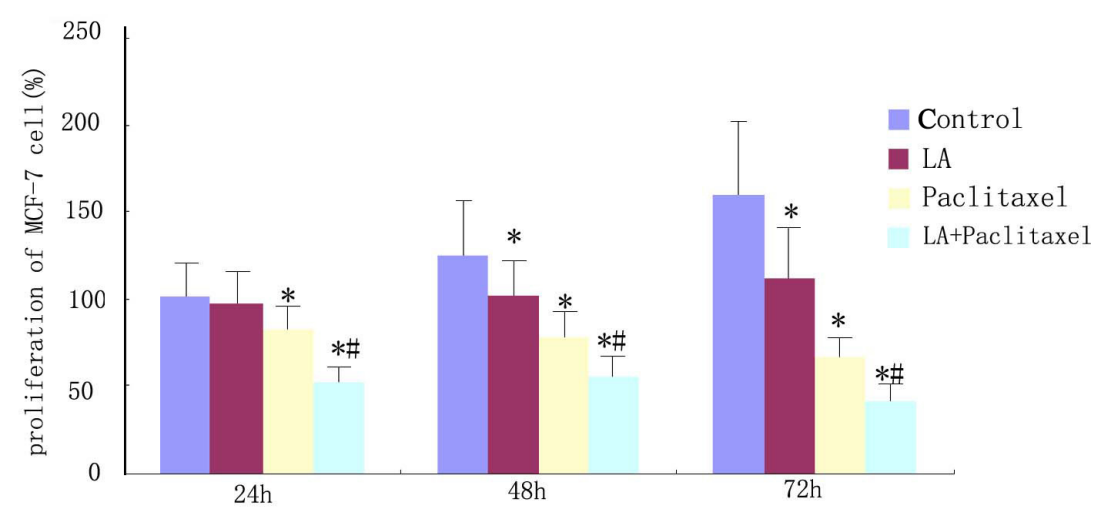

Figure 1. Effect of lipoic acid and paclitaxel on breast cancer cell proliferation. ${ }^{*} \mathrm{P}<0.05$, compared with control; $\mathrm{F}<<$ 0.05 , compared with paclitaxel alone group.

\section{Effect of LA and paclitaxel on breast cancer cell colony formation}

A colony formation assay was used to detect effect of LA alone or in combination with paclitaxel on MCF-7 cell colony formation rate. LA alone could obviously inhibit tumor cell colony formation rate with time dependence $(P<0.05)$. Combined LA and paclitaxel for $24 \mathrm{~h}$ could suppress breast cancer cell colony formation rate more significantly than paclitaxel alone, in a time-dependent manner $(P<0.05)$. LA could restrain breast cancer cell proliferation and colony formation. Combination of LA and paclitaxel could inhibit breast cancer cell growth (Figure 2).

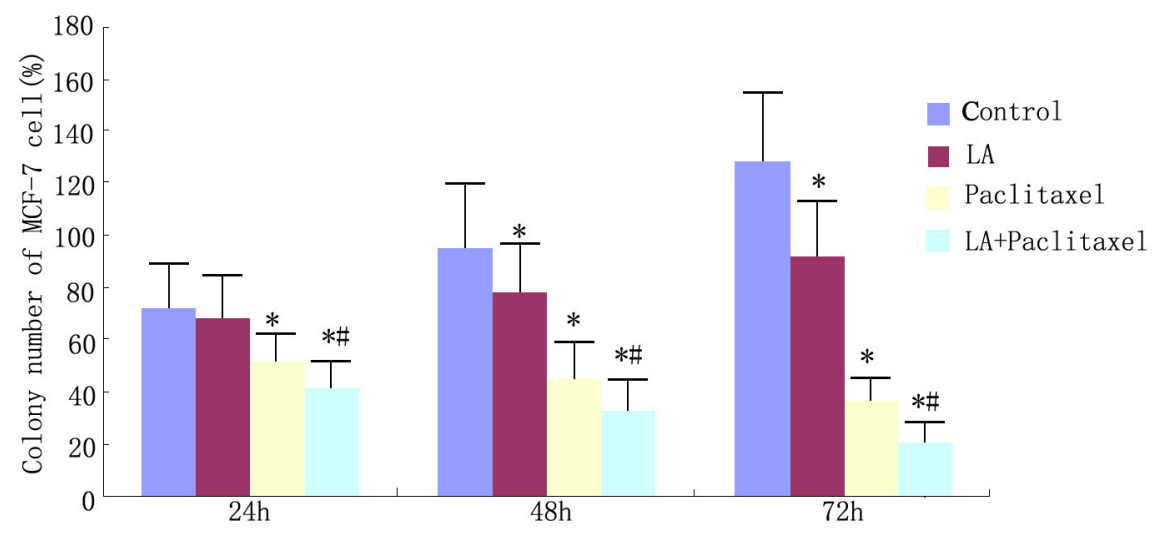

Figure 2. Effect of lipoic acid and paclitaxel on breast cancer cell colony formation. ${ }^{*} \mathrm{P}<0.05$, compared with control; \#P $<0.05$, compared with paclitaxel alone group. 


\section{LA and paclitaxel effect on NF-kB expression in breast cancer cell}

Western blot was performed to analyze NF-kB expression in breast cancer cells after LA or paclitaxel treatment for $48 \mathrm{~h}$. LA alone could decrease NF-kB expression in breast cancer cells but without statistical significance $(P>0.05)$. Paclitaxel alone could obviously reduce NF- $\kappa B$ expression $(P<$ $0.05)$. Combined LA and paclitaxel could decrease NF-kB expression more significantly than paclitaxel alone, and expression was lower than in the control group $(P<0.05$, Figure 3$)$, suggesting that combined LA and paclitaxel may suppress breast cancer cell proliferation through the NF-kB signaling pathway.

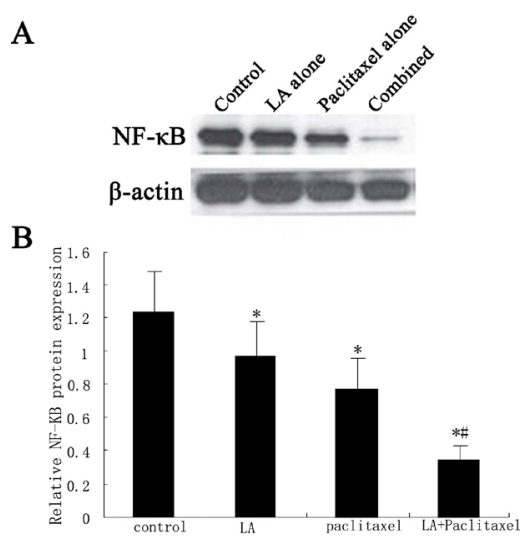

Figure 3. Effect of lipoic acid and paclitaxel on nuclear factor (NF)-кB expression in breast cancer cell. A. The protein level of NF-KB was determined by Western blot. B. The expression of NF-kB mRNA was evaluated by real-time PCR. ${ }^{*} \mathrm{P}<0.05$, compared with control; ${ }^{\mathrm{P}}<0.05$, compared with paclitaxel alone group.

\section{DISCUSSION}

As a highly effective cytotoxin, paclitaxel has a broad spectrum and effective anti-tumor effect on lung cancer, melanoma, ovarian cancer, breast cancer, cervical cancer, and other tumors. Its antitumor effect is higher than that of cisplatin, fluorouracil, and other commonly used drugs. Paclitaxel has immunoregulatory activity. Therefore, it could be used alone or combined with other drugs in the treatment of breast cancer, as an adjuvant therapy in early breast cancer or as second-line treatment of metastatic breast cancer (Jin et al., 2015) (Jin et al., 2015). However, with the promotion of clinical application, it was found that breast cancer can generate drug resistance, and side effects may appear in a dose-dependent manner (Zhang et al., 2015) (Zhang et al., 2015). Thus, reasonable drug selection and their combined application to enhance sensitivity are important in clinical practice.

As a powerful antioxidant, LA can play a physiological role by removing chemical toxicants, scavenging free radicals and reactive oxygen species, inhibiting the production of oxygen free radicals, and improving blood circulation (Zhang et al., 2014; Taneka et al., 2015) (Zhang et al., 2014; Tanaka et al., 2015). Recent research confirmed that it has inhibitory effect on a variety of tumor cells. LA alone or combined with a chemotherapy drug can inhibit colon cancer and cervical cancer cells proliferation. LA may affect tumor through regulating NF-кB (Damnjanovic et al., 2014; Li et al., 2015) (Damnjanovic et al., 2014; Li et al., 2015). NF-kB belongs to the set of nucleoprotein factors that has a multidirectional transcription-regulating effect. It is found in a variety of tissues and cells, and plays a number of pathophysiological roles in cell proliferation, immunity, inflammation, 
and apoptosis (Pal et al., 2014; Tong et al., 2015) (Pal et al., 2014; Tong et al., 2015).

Our results confirmed that LA alone could inhibit breast cancer cell proliferation and colony formation in a time-dependent manner. Compared with paclitaxel alone, LA and paclitaxel in combination can strengthen the inhibitory effect on tumor cells. LA alone or combined with paclitaxel may inhibit NF-kB expression.

In conclusion, LA and paclitaxel in combination could increase the inhibitory effect on breast cancer cell proliferation by regulating the $\mathrm{NF}-\kappa \mathrm{B}$ signaling pathway. This may provide a basis for chemotherapy drug choice in the clinical treatment of breast cancer.

\section{Conflicts of interest}

The authors declare no conflict of interest.

\section{ACKNOWLEDGMENTS}

We thank the anonymous reviewers for reviewing this manuscript.

\section{REFERENCES}

Abouharb S and Moulder S (2015). Metaplastic breast cancer: clinical overview and molecular aberrations for potential targeted therapy. Curr. Oncol. Rep. 17: 431.

Asci H, Saygin M, Cankara FN, Bayram D, et al. (2015). The impact of alpha-lipoic acid on amikacin-induced nephrotoxicity. Ren. Fail. 37: 117-121.

Bingham PM, Stuart SD and Zachar Z (2014). Lipoic acid and lipoic acid analogs in cancer metabolism and chemotherapy. Expert Rev. Clin. Pharmacol. 7: 837-846.

Carbognin L, Sperduti I, Nortilli R, Brunelli M, et al. (2015). Balancing activity and tolerability of neoadjuvant paclitaxel- and docetaxel-based chemotherapy for HER2-positive early stage breast cancer: sensitivity analysis of randomized trials. Cancer Treat. Rev 41: 262-270.

Damnjanovic I, Kocic G, Najman S, Stojanovic S, et al. (2014). Chemopreventive potential of alpha lipoic acid in the treatment of colon and cervix cancer cell lines. Bratisl. Lek. Listy. 115: 611-616.

Golubnitschaja O, Yeghiazaryan K, Costigliola V, Trog D, et al. (2013). Risk assessment, disease prevention and personalised treatments in breast cancer: is clinically qualified integrative approach in the horizon? EPMA J. 4: 6.

Jin H, Park MH and Kim SM (2015). 3,3'-Diindolylmethane potentiates paclitaxel-induced antitumor effects on gastric cancer cells through the Akt/FOXM1 signaling cascade. Oncol. Rep 33: 2031-2036.

Khurshid A, Faridi N, Arif AM, Naqvi H, et al. (2013). Breast lesions in adolescents and young women in Pakistan-a 5 year study of significance of early recognition. Asian Pac. J. Cancer Prev. 14: 3465-3467.

Li J, Zhang BN, Fan JH, Pang Y, et al. (2011). A nation-wide multicenter 10-year (1999-2008) retrospective clinical epidemiological study of female breast cancer in China. BMC Cancer 11: 364.

Li Y, Yan H, Zhang Z, Zhang G, et al. (2015). Andrographolide derivative AL-1 improves insulin resistance through downregulation of NF-kappaB signalling pathway. Br. J. Pharmacol. 172: 3151-3158.

Lim SJ, Choi HG, Jeon CK and Kim SH (2015). Increased chemoresistance to paclitaxel in the MCF10AT series of human breast epithelial cancer cells. Oncol. Rep. 33: 2023-2030.

Pal S, Bhattacharjee A, Ali A, Mandal NC, et al. (2014). Chronic inflammation and cancer: potential chemoprevention through nuclear factor kappa B and p53 mutual antagonism. J. Inflamm. (Lond) 11: 23.

Park SO, Yoo YB, Kim YH, Baek KJ, et al. (2015). Effects of combination therapy of docetaxel with selenium on the human breast cancer cell lines MDA-MB-231 and MCF-7. Ann. Surg. Treat. Res. 88: 55-62.

Ricciardi GR, Russo A, Franchina T, Ferraro G, et al. (2015). Efficacy of nab-paclitaxel plus trastuzumab in a long-surviving heavily pretreated HER2-positive breast cancer patient with brain metastases. Onco. Targets Ther. 8: 289-294.

Tanaka Y, Kaibori M, Miki H, Nakatake R, et al. (2015). Alpha-lipoic acid exerts a liver-protective effect in acute liver injury rats. J. Surg. Res. 193: 675-683.

Tang S, Yin Q, Su J, Sun H, et al. (2015). Inhibition of metastasis and growth of breast cancer by pH-sensitive poly (beta-amino ester) nanoparticles co-delivering two siRNA and paclitaxel. Biomaterials 48: 1-15. 
Tong L, Yuan Y and Wu S (2015). Therapeutic microRNAs targeting the NF-kappa B signaling circuits of cancers. Adv. Drug Deliv. Rev. 81: 1-15.

Wardle J, Robb K, Vernon S and Waller J (2015). Screening for prevention and early diagnosis of cancer. Am. Psychol 70 : 119-133.

Wei XQ, Li X, Xin XJ, Tong ZS, et al. (2013). Clinical features and survival analysis of very young (age<35) breast cancer patients. Asian Pac. J. Cancer Prev. 14: 5949-5952.

Zhang F, Zhang S, Pollack SF, Li R, et al. (2015). Improving paclitaxel delivery: in vitro and in vivo characterization of PEGylated polyphosphoester-based nanocarriers. J. Am. Chem. Soc. 137: 2056-2066.

Zhang L, Zou J, Chai E, Qi Y, et al. (2014). Alpha-lipoic acid attenuates cardiac hypertrophy via downregulation of PARP-2 and subsequent activation of SIRT-1. Eur. J. Pharmacol. 744: 203-210. 